\title{
Different serving shapes of cooked jasmine rice on a plate affect the consumer's visual preference
}

\author{
Sophitanontrat, W. and *Khajarern, K. \\ Faculty of Interdisciplinary studies, Khon Kaen University, Nong Khai Campus, Nong Khai 43000 Thailand
}

\author{
Article history: \\ Received: 1 June 2021 \\ Received in revised form: 11 \\ July 2021 \\ Accepted: 3 October 2021 \\ Available Online: 28 \\ November 2021
}

Keywords:

Serving shapes,

Cooked jasmine rice,

Visual hedonic preference,

Consumer perception

DOI:

https://doi.org/10.26656/fr.2017.5(6).366

\begin{abstract}
This research aimed to investigate how five different serving shapes of cooked jasmine rice (round, square, triangular, flower, and heart shapes) affected visual hedonic preference and consumer perception $(\mathrm{n}=100)$. Cooked rice was placed on a plate without food, the heart, flower, and triangle serving shapes had higher artistic mean scores than the round shape. And cooked rice placed in the shape of a heart on a plate with food had a higher mean score on 'liking in shape' than round or square shapes. The findings of this study could be beneficial to food styling, presenting, and catering in the foodservice industry, resulting in increased sales, particularly in restaurants and hotels. Furthermore, for more successful food marketing and advertising, one can use the shapes of a heart as a serving shape for cooked jasmine rice box labels.
\end{abstract}

\section{Introduction}

Food preferences are impacted by a variety of factors, including sensory characteristics of the food and the context in which it is consumed (García-Segovia et al., 2015). Several studies, particularly the food styling research by Piqueras-Fiszman et al. (2012), have shown that contextual elements connected with foods and individuals impact food acceptability and consumption. They found that strawberry mousse tasted substantially sweeter when served on a white dish than when served on a black plate. As a result, consumers were more accepting of the mousse given on a white dish. The flavour strength and acceptance vary depending on location and eating circumstances, in relation to the colours of hot chocolate cups.

Furthermore, Piqueras-Fiszman et al. (2013) established that plate colour has a major impact on customer perception of food, but that this varies depending on the type of dessert offered. The effects can't be explained solely in terms of colour contrast; they're also linked to taste. For instance, black chocolate with a strong flavour, or even refined chocolate, could have an effect. Surprisingly, the pattern of admiration for each dessert was consistent across all plates. For all desserts, higher scores were obtained on all qualities.

In modern lifestyles, instant cooked jasmine rice is becoming more popular among all instant foods in the
Thai market. One of the factors to promote Thai jasmine rice is to present it to consumers by displaying and making them available at convenient stores, restaurants and hotels. Do not neglect the concern on how their food looks with styling serving shapes of cooked rice placed on a plate (Piqueras-Fiszman et al., 2012).

Many chefs nowadays serve food on plates in a natural manner, with visualizations of the meal being improved in the kitchen. As a result, scientifically recognizing the impact of consumer expectations (Piqueras-Fiszman and Spence, 2015) and perceptions through variances in the visual style of the food on the plate is becoming increasingly significant (Rowley and Spence, 2018). In fact, in addition to taste and flavour, changes in the aesthetic composition of a dish can influence consumer purchase intent.

Rowley and Spence (2018) demonstrated that when the items were arranged horizontally rather than vertically, the food plate was regarded as having a greater portion. Furthermore, the dessert that was presented in the centre had a greater portion than the offset version of the identical meal. When the food was arranged horizontally and centrally, it was likewise accepted and purchased more by consumer panels. This information is useful for improving a dish's aesthetic appeal in order to boost customer satisfaction and maybe lead to better food choices. 
By using the principle of Arts in food decoration, the arts of food decoration (Darnlapol, 2018) may now improve aesthetic value in appetizing, as well as generate value-added to food and services. It is most typically seen in European food, such as bakery (Whitman, 2001) and confectionery products (Haeringer, 1990), and Thai food (Hiran-akkharawong, 2014), such as Thai jelly, can be seen in desserts. A set of stainless steel moulds for moulding mousse cakes (Gisslen, 2018) is available in the supermarket. For the same reason, it might be used to mould cooked rice.

However, the effect of serving shapes of cooked jasmine rice on the consumer's visual preference has never been studied before especially to serving shapes which were compared with and without food. As a result, it's intriguing to study these impacts on consumer perception and preferences (i.e., how they like serving shape of cooked rice, quantity and overall, how they feel 'cooked rice quantity' and 'look so appetizing' as well as how artistic they think the food looks).

\section{Materials and methods}

\subsection{Subjects}

One hundred university students and staffs [Resurreccion (1998) recommended consumer panel size for various consumer sensory testing laboratory], of which 60 females (mean age was 23.5 \pm 2.9 ) and 40 males (mean age was 23.2 \pm 2.8 ) were recruited using purposive sampling to the sensory laboratory. They had never been trained in sensory testing before. All participants must not have vision health problems.

\subsection{Sample preparation}

Thai Jasmine rice grain (product from B-Herb manufacturing) was selected to cook by conventional rice cooker (OTTO CR-110T Model) following the instructions on the label. All broken grain, abnormal shape, the different colour shade was removed. Only perfect whole kernel rice grains were selected and used. After cooking, cooked jasmine rice were pressed and moulded in five shapes (round, triangle, heart, flower and square) using a set of stainless-steel moulds (product from Jusbe, Yangjiang Jiangcheng Xiangshun hardware factory, China) before placing on the middle of each white round dining plate (Piqueras-Fiszman et al. (2012) with standard diameter 12 inches. The diameters and depths of the moulds were not different (diameter 3.15 inches $/ 8 \mathrm{~cm}$. and depth 0.57 inches $/ 4 \mathrm{~cm}$.). This size is more appropriate for food plating and catering. However, there were more differences for the serving weights of cooked jasmine rice (round shape of cooked rice had a mean weight of $188.29 \pm 0.96 \mathrm{~g}, 119.43 \pm 0.67 \mathrm{~g}$ of triangle shape, $164.64 \pm 0.91 \mathrm{~g}$ of heart shape, $168.14 \pm 0.20 \mathrm{~g}$ of flower shape and $249.37 \pm 0.55 \mathrm{~g}$ of square shape). The digital scale with an accuracy of $0.01 \mathrm{~g}$ was carefully weighed.

The test was divided into two sessions; firstly, mounds of cooked rice were shaped into different shapes that were placed on the plate (1) with and (2) without food (Figure 1). For the second session, each shaped cooked rice was served with approximately $120 \mathrm{~g}$ of Pad Ka Praow Kai [stir fried basil chicken (ready-to-eat; RTD), product from Ezygo, CP-RAM manufacturing which was the most popular Thai food (Thuan, 2020)]. The food was placed beside the cooked rice in the same position on the plate for each treatment.

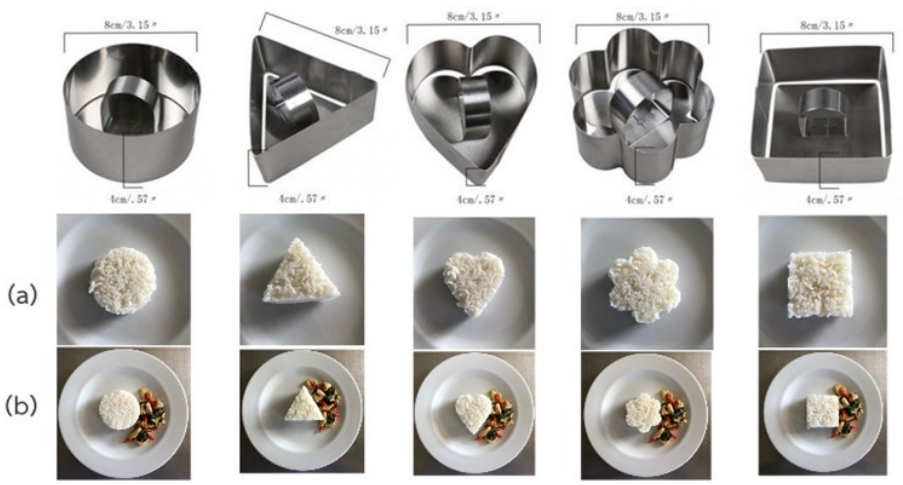

Figure 1. Five serving shapes of cooked rice placed on the plate (round, triangle, heart, flower and square shapes); (a) without food and (b) with food.

\subsection{Consumer study}

Five serving shapes of cooked jasmine rice placed on the plate with and without food were served for visual hedonic preference and consumer perception test using Randomize complete block design (RCBD) (Khajarern, 2013). After looking at its appearance, each of the consumer panels was asked to rate their liked or disliked on each sample on 3 factors such as 'shape of served cooked rice', 'quantity' and 'overall liking' by using a 9point hedonic scale $(1=$ extremely disliked, $5=$ neither liked nor disliked, $9=$ extremely liked) (Meilgaard et al., 2006). The appropriate level of 'amount of cooked rice', 'look so appetizing' and how 'artistic' they believed the dish to look (Michel et al., 2014; Rowley and Spence, 2018), was evaluated using the following 9- point mood scale $(1=$ not at all, to $9=$ very much) (Khajarern, 2013). Finally, consumer panels evaluated their purchasing intention to the samples by using a 5-point structured scale ( 1 = certainly will not buy, $3=$ may or may not buy and $5=$ certainly will buy) (Symmank et al., 2018).

\subsection{Data analysis}

The data from all scales were analyzed using analyses of variance (ANOVA) $(p \leq 0.05)$ considering sample and block as sources of variation by SPSS/PC for Windows Version 26.0 developed by SPSS Inc., 
Chicago, USA. The level of significance for all statistical analyses was set at 0.05 . Pearson's correlation coefficients (Rowley and Spence, 2018) were used to estimate the relationships among mean scores of all attributes and instrumental data.

\section{Results and discussion}

For reliability of the test, the total-item Cronbach's alpha of the scale by this consumer panel group, over 2 testing sessions were slightly different (Cronbach's alpha without food $=0.911$ and with food $=0.915$ ). This result indicated that the scale internal consistency and reliability was good or high according to George and Mallery (2003).

The result of 'how different serving shapes of cooked rice placed on the plate with and without food affect the visual hedonic preference and consumer perception' was shown in Figure 2. It showed that all serving shapes of cooked jasmine rice with and without food were not different for all attributes.

However, mean responses for different serving shapes of cooked jasmine rice without food were found that there was a significant difference in terms of ratings on how artistic, cooked rice serving in the heart, flower and triangle shapes had the highest mean artistic scores (Figure 2). When each of the cooked jasmine rice was shaped and served with food on the plate. The result showed that all rice shapes were not different for most of the attributes. However, only cooked rice in heart shape had the highest mean shape liking score (Figure 2). Food may help to highlight each shape dominantly. And mean artistic scores were not different due to the food type which was used for this research, it is a common Thai food (stir-fried basil chicken, it is the most popular Thai food for regular consumption). Thus, luxury or fine dining food for consumer image should be selected to serve with the cooked jasmine rice in future experiments. This result might be supported by several reports which indicated that the meaning of heart image for the consumer was 'love', 'happiness' and 'benefit for health' (Miklavec et al., 2021). For triangle shape, it looked like a heart shape while the flower shape was characterized by enhancing 'happiness' (Huss et al., 2017). It is worth noting that the triangle shape was viewed as having the same amount of servings as any other shape. Even though, its weight is lower than other shapes. This information should be helpful for consumers who want to diet. For square shape, it was a geometric shape which meant 'in the frame', 'limit' and 'not relax', and its commonness can seem boring (Özçakır et al., 2019) include it contained more rice than other shapes in the same size. For round shape, it was widely used for moulding cooked rice and very familiar for consumers.

The mean score of each attribute showed a high relationship to the overall liking mean scores by Pearson correlation coefficient (Table 1). From this positive relationship, it could be assumed that the cooked rice which induced 'like in shape' and 'artistic', was preferred more and given a higher score for 'purchase intent' by the consumer panels.

\section{Conclusion}

From the investigation of 'how five different serving shapes of cooked jasmine rice affected visual hedonic preference and consumer perception', it was found that cooked rice was placed on a plate without food, the heart, flower, and triangle serving shapes had higher artistic mean scores than the round shape. And cooked

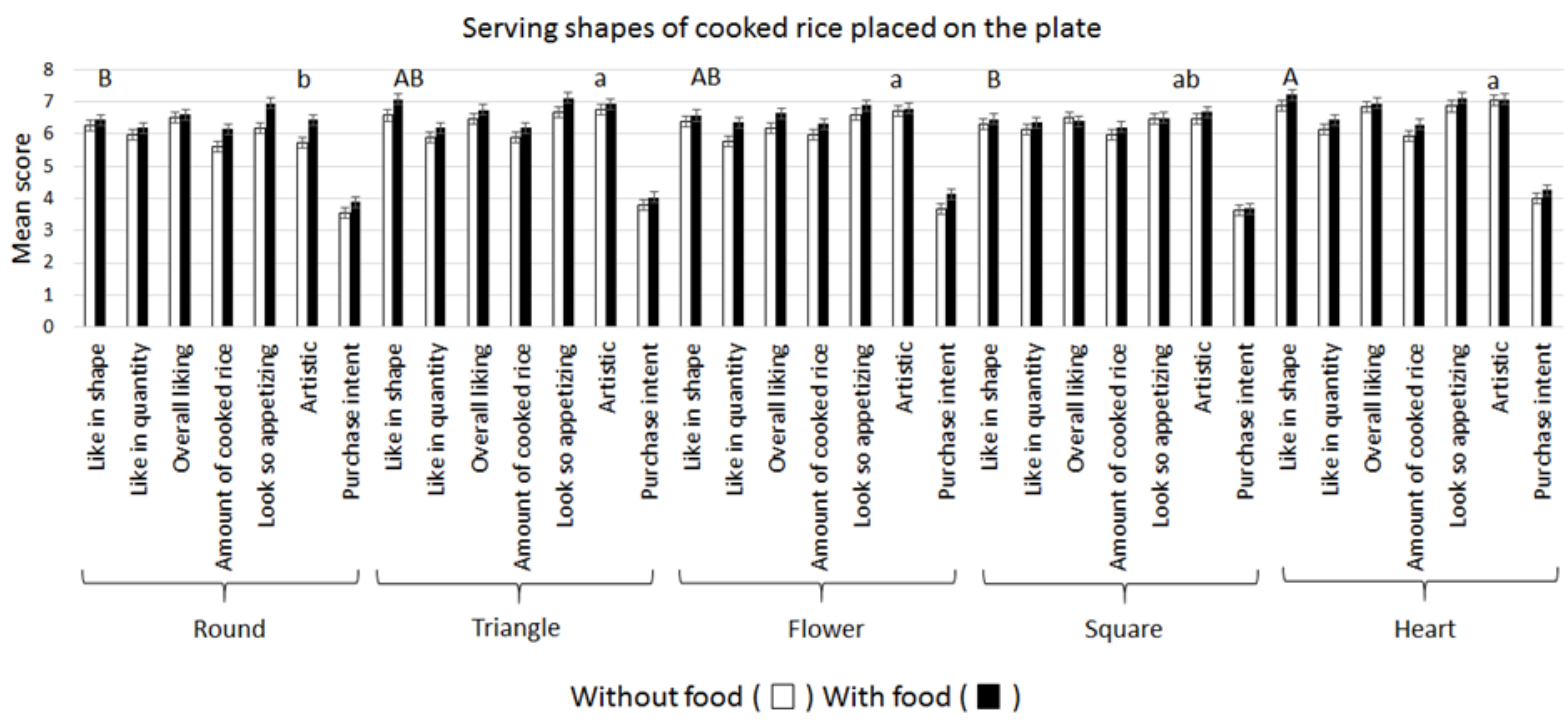

Figure 2. Mean responses for each attribute of five serving shapes of cooked rice placed on the plate with and without food. Bars with uppercase alphabet notations are statistically different among samples (with food) for 'like in shape' at $\alpha=0.01$ while bars with lowercase alphabet notations are statistically different among samples (without food) for 'artistic' at $\alpha=0.01$. 
Table 1. Pearson correlation coefficients between overall liking and each attribute item of both sessions.

\begin{tabular}{lcccc}
\hline \multirow{2}{*}{ Attributes } & \multicolumn{2}{c}{ Overall liking } & \multicolumn{2}{c}{ Purchase intent } \\
\cline { 2 - 5 } & Without food & With food & Without food & With food \\
\hline Like in shape & $0.814^{* *}$ & $0.814^{* *}$ & $0.545^{* *}$ & $0.524^{* *}$ \\
Like in quantity & $0.621^{* *}$ & $0.621^{* *}$ & $0.329^{* *}$ & $0.415^{* *}$ \\
Amount of cooked rice & $0.602^{* *}$ & $0.602^{* *}$ & $0.407^{* *}$ & $0.438^{* *}$ \\
Look so appetizing & $0.703^{* *}$ & $0.703^{* *}$ & $0.606^{* *}$ & $0.670^{* *}$ \\
Artistic & $0.654^{* *}$ & $0.654^{* *}$ & $0.510^{* *}$ & $0.601^{* *}$ \\
Purchase intent & $0.584^{* *}$ & $0.584^{* *}$ & $1.000^{* *}$ & $1.000^{* *}$ \\
\hline
\end{tabular}

** Correlation was significant at the 0.01 level (2-tailed).

rice placed in the shape of a heart on a plate with food had a higher mean score on 'liking in shape' than round or square shapes. These results might benefit food styling, presenting and catering of cooked jasmine rice in the foodservice industry especially for convenience stores (ready to eat food box styling), restaurants and hotels.

In addition, this result would benefit food marketing and advertising of jasmine grain rice products by labelling cooked jasmine rice pictures on the packaging, especially for artistic consumers. However, the type of food should be screened appropriately to present with the shaped rice. Finally, a limited number of moulds were used and were widely available as a set in most of the markets. Other shapes such as stars, fruit and cartoon (but they should be the same size) should be used to investigate in future experiments.

\section{References}

Darnlapol, N. (2018). Arts of Thai fusion food decoration. Graduate Studies Journal, 15(71), 1-13.

García-Segovia, P., Harrington, R.J. and Seo, H.S. (2015). Influences of table setting and eating location on food acceptance and intake. Food Quality and Preference, 39, 1-7. https:// doi.org/10.1016/j.foodqual.2014.06.004

George, G. and Mallery, P. (2003). SPSS for Windows step by step: a simple guide and reference 11.0 update. Boston, USA: Allyn and Bacon.

Gisslen, W. (2018). Professional Cooking. $9^{\text {th }}$ ed. Hoboken, New Jersey, USA: John Wiley and Sons, Inc.

Haeringer, J. (1990). Les Desserts. Chicago, Illinois, USA: FM2.

Hiran-akkharawong, I. (2014). Development of Crispy Jelly Product form Fresh Coconut Syrup. Bangkok: Rajamangala University of Technology Phra Nakhon.

Huss, E., Yosef, K.B. and Zaccai, M. (2017). The Meaning of Flowers: A Cultural and Perceptual Exploration of Ornamental Flowers. The Open Psychology Journal, 10(1), 140-153. https:// doi.org/10.2174/1874350101710010140

Khajarern, K. (2013). Using sensory and mood perceptual maps for generating new energy drink product ideas. International Food Research Journal, 20(1), 175-181.

Meilgaard, M., Civille, G.V. and Carr, B.T. (2006). Sensory Evaluation Techniques. $4^{\text {st }}$ ed. USA: CRC Press. https://doi.org/10.1201/b16452

Michel, C., Velasco, C., Gatti, E. and Spence, C. (2014). A taste of Kandinsky. Assessing the influence of the artistic visual presentation of food on the dining experience. Flavour, 3(7), 1-10. https:// doi.org/10.1186/2044-7248-3-7

Miklavec, K., Hribar, M., Kušar, A. and Pravst, I. (2021). Heart Images on Food Labels: A Health Claim or Not? Foods, 10, 643. https:// doi.org/10.3390/foods10030643

Özçakır, B., Konca, A.S. and Arıkan, N. (2019). Children's geometric understanding through digital activities: The case of basic geometric shapes. International Journal of Progressive Education, 15 (3), 108-122. https://doi.org/10.29329/ ijpe.2019.193.8

Piqueras-Fiszman, B., Alcaide, J., Roura, E. and Spence, C. (2012). Is it the plate or is it the food? Assessing the influence of the colour (black or white) and shape of the plate on the perception of the food placed on it. Food Quality and Preference, 24(1), 205-208.

https://doi.org/10.1016/

j.foodqual.2011.08.011

Piqueras-Fiszman, B., Giboreau, A. and Spence, C. (2013). Assessing the influence of the colour of the plate on the perception of a complex food in a restaurant setting. Flavour, 2, 24 . https:// doi.org/10.1186/2044-7248-2-24

Piqueras-Fiszman, B. and Spence, C. (2015). Sensory expectations based on product extrinsic Food cues: An interdisciplinary review of the empirical evidence and theoretical accounts. Food Quality and Preference, 40(Part A), 165-179. https:// doi.org/10.1016/j.foodqual.2014.09.013

Resurreccion, A.V.A. (1998). Consumer Sensory Testing for Product Development. Gaithersburg, USA: 
Aspen Publication.

Rowley, J. and Spence, C. (2018). Does the visual composition of a dish influence the perception of portion size and hedonic preference? Appetite, 128, 79-86. https://doi.org/10.1016/j.appet.2018.06.005

Symmank, C., Zahn, S. and Rohm, H. (2018). Visually suboptimal bananas: How ripeness affects consumer expectation and perception. Appetite, 120, 472-481. https://doi.org/10.1016/j.appet.2017.10.002

Thuan, W. (2020). Top 10 Thai Food - Most Popular Thai Foods. Retrieved on October 21, 2020, from Wikipedia Website: https://th.wikipedia.org.

Whitman, R. (2001). 4-H Cake Decorating. Laramie, Wyoming, USA: Wilton Enterprises, Inc. 